\title{
Glutaraldehyde as a crosslinking agent for collagen-based biomaterials
}

\author{
L. H. H. OLDE DAMINK, P. J. DIJKSTRA, M. J. A. VAN LUYN*, \\ P. B. VAN WACHEM*, P. NIEUWENHUIS*, J. FEIJEN \\ Department of Chemical Technology, University of Twente, P.O. Box 217, 7500 AE, \\ Enschede, The Netherlands \\ *Department of Histology and Cell Biology, University of Groningen, Oostersingel 69/2, \\ 9713 EZ, Groningen, The Netherlands
}

The formation of Schiff bases during crosslinking of dermal sheep collagen (DSC) with glutaraldehyde (GA), their stability and their reactivity towards GA was studied. All available free amine groups had reacted with GA to form a Schiff base within 5 min after the start of the reaction under the conditions studied $(0.5 \%(\mathrm{w} / \mathrm{w}) \mathrm{GA})$. Before crosslinks are formed the hydrolysable Schiff bases initially present were stabilized by further reaction with $\mathrm{GA}$ molecules. An increase in shrinkage temperature $\left(T_{\mathrm{s}}\right)$ from $56^{\circ} \mathrm{C}$ for non-crosslinked DSC (N-DSC) to $78^{\circ} \mathrm{C}$ for GA crosslinked DSC (G-DSC) was achieved after crosslinking for $1 \mathrm{~h}$. From the relationship between the free amine group content and the $T_{\mathrm{s}}$ during crosslinking it was concluded that higher GA concentrations and longer reaction times will result in the introduction of pendant-GA-related molecules rather than crosslinks. After $24 \mathrm{~h}$ crosslinking an average uptake of $3 \mathrm{GA}$ molecules per reacted amine group was found. No increase in the tensile strength of the materials was observed after crosslinking, which may be a result of formation of crosslinks within the fibres rather than in between fibres. Aligning of the fibres by applying a pre-strain to the samples and subsequent crosslinking yielded materials with an increased tensile strength.

\section{Introduction}

Glutaraldehyde (GA) is commonly used as a crosslinking agent for collagen-based biomaterials [1-4]. A large variety of reaction pathways may be involved in this crosslinking as is shown in Scheme 1. The problems encountered in determining the course of the reaction and the difficult characterization of the products formed has impeded the complete elucidation of the reaction mechanism involved. Furthermore it has been suggested that due to the use of impure GA solutions in the crosslinking reactions, results obtained by different groups may be difficult to compare [5].

It is generally assumed that GA crosslinking of collagen (Scheme 1) takes place through reaction of the aldehyde groups of GA (II) with the $\varepsilon$-amine groups of lysine or hydroxylysine residues (I) [6-8]. This reaction will result in the formation of a Schiff base intermediate (III). Cheung et al. $[4,8]$ suggested that Schiff bases are stable under the crosslinking conditions and crosslinking involves the formation of GA polymers (IV) due to aldol condensation reactions. In addition, the formation of an $\alpha-\beta$ unsaturated Schiff base intermediate (V) followed by Michael addition of a collagen amine group with the unsaturated group of $\mathrm{V}$ to give VI results in the formation of a crosslink. Furthermore, formation of a crosslink is possible by the reaction of amine groups with the free aldehyde groups of V to give VII $(n=0)$, or a free aldehyde group remaining after aldol polymerization of $\mathrm{V}$ to give VII $(n>0)$.

Others [9-11] claim that Schiff bases are unstable intermediates that react further during the crosslinking reaction. A Mannich-type reaction between a protonated Schiff base and a GA-related enol, resulting in the formation of a secondary amine (VIII), has been suggested $[9,11]$. After aldol condensation and subsequent reaction with collagen amine groups the formation of aliphatic crosslinks (as given in IX) is possible. Furthermore, after reaction of VIII with another GA molecule and ring closure, a six-membered dihydropyridine can be formed [9]. Oxidation of dihydropyridine type crosslinks by oxygen present in the crosslinking solution [12] can result in the formation of substituted quaternary pyridinium type crosslinks $(\mathrm{X})$. Although the 1, 3, 4,5 substituted entity is shown, a 1,2, 3, 5 substitution pattern is also possible [9]. Similar to the formation of the quaternary pyridinium crosslink after GA crosslinking of ovalbumine [13] structure XI represents the formation of a crosslink after reaction of $\mathrm{V}$ with a collagen free amine group. Lubig et al. suggested the formation of a-oxo-N-alkyl piperidine crosslinks (XIII) after condensation of $\mathrm{N}$-alkyl-2,6-dihydroxy piperidine (XII) with cyclic monohydrated GA. In a side reaction the formation of pyridinium XIV was described [6]. 


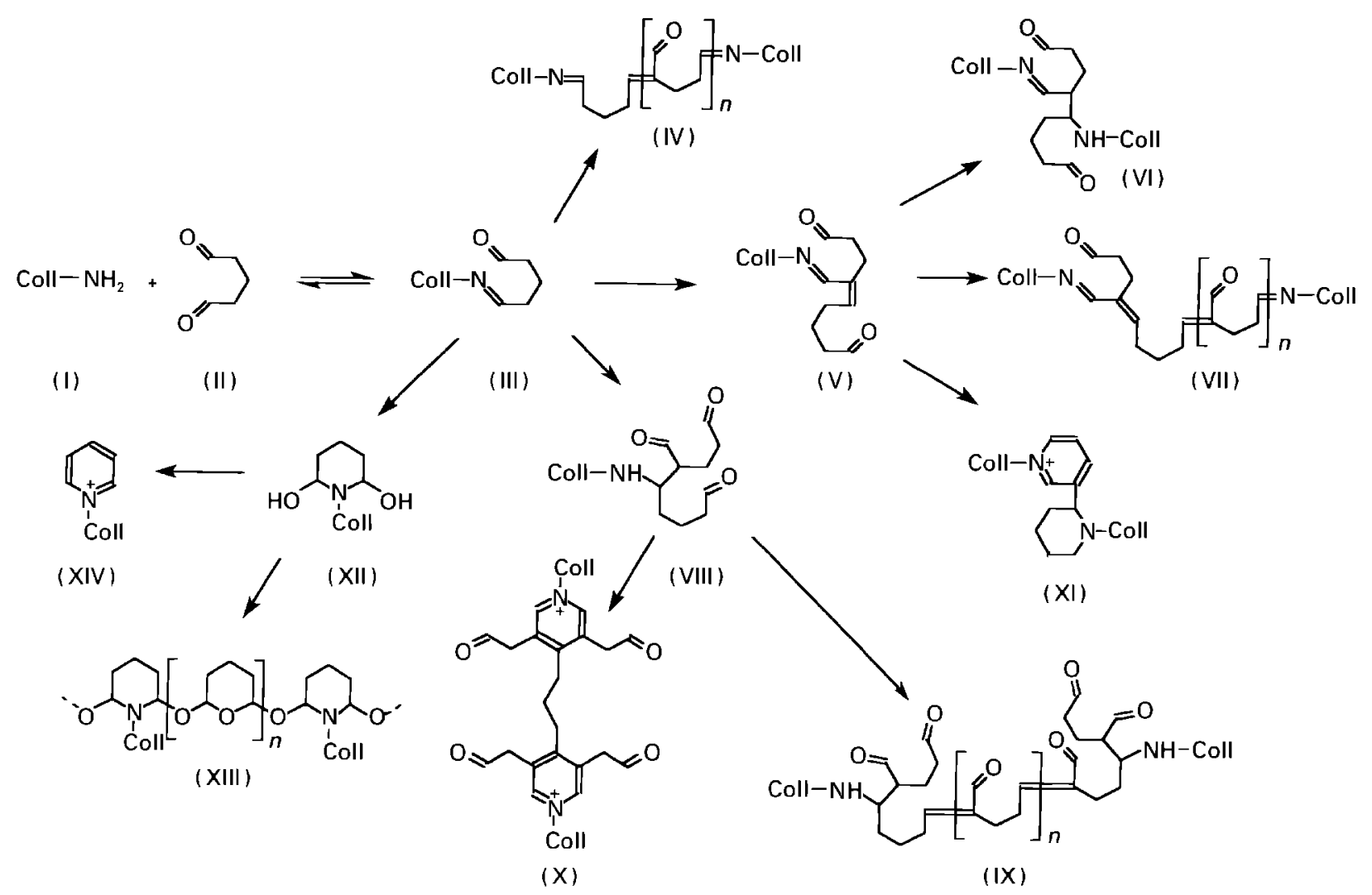

Scheme 1.

The formation of Schiff bases, their stability during crosslinking and their reactivity towards GA was recently investigated and the results are described in this paper. The relationship between the degree of crosslinking and the number of free amine groups present in the polypeptide chains has been used to discuss the course of the crosslinking.

\section{Materials and methods}

\subsection{Purification of dermal sheep collagen}

Dermal sheep collagen (DSC) was obtained from the Zuid-Nederlandse Zeemlederfabriek (Oosterhout, The Netherlands). In brief, the sheep skin was depilated and immersed in a lime-sodium sulphide solution to remove the epidermis. Non-collageneous substances were removed using proteolytic enzymes whereafter the skin was split to obtain the dermal layer [14]. The remaining fibrous collagen network was washed four times with water, twice with acetone and twice with water before it was frozen and lyophilized to give non-crosslinked DSC (N-DSC). The collagen thus obtained shows the native banding and is resistant to trypsine digestion.

\subsection{Crosslinking}

Glutaraldehyde (GA, 25\% aqueous solution z.S., Merck-Schuchardt, Hohenbrunn, FRG) was purified by distillation (b.p. $7075^{\circ} \mathrm{C}, 13 \mathrm{mmHg}$ ) before use. Ultraviolet measurements of the purified GA showed only one absorption peak at $280 \mathrm{~nm}$ indicating that aldol condensation products (absorption peak at $235 \mathrm{~nm}$ ) were removed by distillation.

\subsubsection{General procedure}

In a typical experiment $\mathrm{N}$-DSC samples weighing $1 \mathrm{~g}$ were crosslinked in $100 \mathrm{ml}$ of a $0.5 \%$ (w/w) GA solution in phosphate buffer $\left(0.054 \mathrm{M} \mathrm{Na}_{2} \mathrm{HPO}_{4}, 0.013 \mathrm{M}\right.$ $\mathrm{NaH}_{2} \mathrm{PO}_{4}, \mathrm{pH} 7.4$ ) for $1 \mathrm{~h}$ at room temperature (RT). After crosslinking, the G-DSC samples were rinsed for 30 min by running tap water, washed twice for $30 \mathrm{~min}$ with $4 \mathrm{M} \mathrm{NaCl}$ and washed four times for $30 \mathrm{~min}$ with distilled water to hydrolyse any Schiff base and remove unreacted GA before lyophilization. The GA concentration in the washing water of the final washing step was less than $0.2 \mathrm{ppm}$ as determined with the GA assay described in Section 2.3.

In order to study the kinetics of the GA crosslinking both the free amine group content and the $T_{\mathrm{s}}$ of G-DSC samples were monitored for time periods upto $48 \mathrm{~h}$. The influence of the $\mathrm{pH}$ of the crosslinking solution on the free amine group content and the $T_{\mathrm{s}}$ was determined at $\mathrm{pH}$ values between 5 and $9(0.07 \mathrm{M}$ $\mathrm{NaH}_{2} \mathrm{PO}_{4}$ adjusted with $\mathrm{NaOH}$ ). N-DSC samples were crosslinked for $1 \mathrm{~h}$. To study the influence of the GA concentration on the free amine group content and the $T_{\mathrm{s}}$, N-DSC samples were crosslinked at GA concentrations of $0.05,0.1,0.5,1.0$ and $1.5 \%(\mathrm{w} / \mathrm{w})$, respectively.

Reduction of the Schiff bases present after crosslinking $\mathrm{N}$-DSC with GA was established by reaction with $\mathrm{NaBH}_{4}$ (Janssen Chimica, Beerse, Belgium). The G-DSC samples obtained were immersed directly after crosslinking in a freshly prepared $1.2 \mathrm{mg} / \mathrm{ml}$ solution of $\mathrm{NaBH}_{4}$ in phosphate buffer ( $\mathrm{pH}$ 7.4) for $1 \mathrm{~h}$.

Trapping of Schiff bases formed during the reaction of N-DSC with GA was performed using a phosphate buffer solution ( $\mathrm{pH} 7.4$ ) containing $0.5 \%$ (w/w) GA and $1 \mathrm{mg} / \mathrm{ml} \mathrm{NaCNBH}{ }_{3}$ (Janssen Chimica, Beerse, 
Belgium). Reaction times were varied between 0 and $60 \mathrm{~min}$.

\subsection{Depletion measurements}

The depletion of GA from the crosslinking solutions was measured by assaying the crosslinking solution at different time intervals using the colorimetrical method described by Huang-Lee et al. [15]. Crosslinking was performed by immersing N-DSC samples weighing $1 \mathrm{~g}$ in $50 \mathrm{ml}$ of a $0.5 \%(\mathrm{w} / \mathrm{w}) \mathrm{GA}$ solution in phosphate buffer $(\mathrm{pH} 7.4)$ at room temperature. At the desired time interval, the G-DSC samples were quickly reacted with $\mathrm{NaBH}_{4}$ as described above before determination of their free amine group content (see Section 2.4).

A $0.25 \mathrm{ml}$ sample was diluted by adding $24.75 \mathrm{ml}$ phosphate buffer $\left(0.054 \mathrm{M} \quad \mathrm{Na}_{2} \mathrm{HPO}_{4}, \quad 0.013 \mathrm{M}\right.$ $\mathrm{NaH}_{2} \mathrm{PO}_{4}, \mathrm{pH}$ 7.4). Samples $(2.0 \mathrm{ml})$ of the diluted solutions were reacted with $2.0 \mathrm{ml}$ of a $100 \mathrm{mM}$ 6-aminohexanoic acid solution (z.S., MerckSchuchardt, Hohenbrunn, FRG) in water at $90^{\circ} \mathrm{C}$ for $90 \mathrm{~min}$. After cooling, the absorbance at $253 \mathrm{~nm}$ was measured against a control sample which contained no GA (Uvikon 930 spectrophotometer, Kontron Instruments, Switzerland). A standard curve was prepared using purified glutaraldehyde (GA) in phosphate buffer $\left(0.054 \mathrm{M} \mathrm{Na}_{2} \mathrm{HPO}_{4}, 0.013 \mathrm{M} \mathrm{NaH}_{2} \mathrm{PO}_{4}\right.$, $\mathrm{pH} 7.4$ ) in the concentration range from 0 to $1 \mathrm{mM}$. Then $2.0 \mathrm{ml}$ samples were reacted as described above.

The influence of aldol polymers present in GA solutions on the slope of the standard curve was determined using solutions of purified GA which were heated for $1,3,5,10,15$ and $20 \mathrm{~min}$ at $90^{\circ} \mathrm{C}$. The amount of aldol polymers present was related to the purification index (PI) defined as the ratio between the absorbance of the GA solution at $235 \mathrm{~nm}$ (aldol polymers) and $280 \mathrm{~nm}$ (monomer) [5, 16]. After cooling of the resulting solutions standard curves were made according to the procedure described above.

\subsection{Characterization}

\subsection{Degree of crosslinking}

The degree of crosslinking of the DSC samples was related to the increase in shrinkage temperature [17] after crosslinking with GA. Shrinkage temperatures $\left(T_{\mathrm{s}}\right)$ of crosslinked or non-crosslinked DSC samples immersed in water were determined using an apparatus similar to that described in IUP/16 [18]. Test specimens were cut $(5 \mathrm{~mm} \times 50 \mathrm{~mm})$, mounted and hydrated for at least $30 \mathrm{~min}$. A heating rate of $2.5^{\circ} \mathrm{C} / \mathrm{min}$ was applied and the onset of shrinkage was recorded as the $T_{\mathrm{s}}$

\subsubsection{Free amine group content}

The primary amine group content of crosslinked and non-crosslinked DSC samples, expressed as the number of free amine groups present per 1000 amino acids $(n / 1000)$, was determined using 2,4,6-trinitrobenzenesulfonic acid (TNBS) [19]. To a sample of 2-4 mg of DSC subsequently $1.0 \mathrm{ml}$ of a $4 \%(\mathrm{w} / \mathrm{v}) \mathrm{NaHCO}_{3}$ (p.a., Merck, Darmstadt, FRG) solution and $1.0 \mathrm{ml}$ of a freshly prepared $0.5 \%(\mathrm{w} / \mathrm{v})$ TNBS (analytical grade, Serva, Heidelberg, FRG) solution in distilled water was added. After reaction for $2 \mathrm{~h}$ at $40{ }^{\circ} \mathrm{C}, 3.0 \mathrm{ml}$ of $6 \mathrm{M} \mathrm{HCl}$ was added and the temperature was raised to $60^{\circ} \mathrm{C}$. Solubilization of DSC was achieved within $90 \mathrm{~min}$. The resulting solution was diluted with $5.0 \mathrm{ml}$ distilled water and the absorbance measured at $345 \mathrm{~nm}$. A control was prepared applying the same procedure except that $\mathrm{HCl}$ was added before the addition of TNBS. The free amine group content was calculated using a molar absorption coefficient of $14.6001 \mathrm{~mol}^{-1} \mathrm{~cm}^{-1}$ for trinitrophenyllysine [20]. Extraction of the hydrolyzed DSC solution with diethyl ether did not influence the absorbance reading and was thus omitted.

\subsection{Mechanical properties}

Stress-strain curves of DSC samples were determined by uniaxial measurements using an Instron mechanical tester. Because of variations in the mechanical properties of different parts of the sheep skin [21], the change in mechanical properties of the samples after crosslinking was only compared with the mechanical properties of matching non-crosslinked controls taken from adjacent parts of the skin. Samples used to study the influence of crosslinking on the mechanical properties were always taken from the IUP/2 [22] sampling area parallel to the backbone and were either crosslinked or kept as control.

The mechanical properties as a function of the degree of crosslinking of G-DSC samples was studied. Samples with different degrees of crosslinking were obtained by immersing N-DSC samples for $1 \mathrm{~h}$ in phosphate buffer ( $\mathrm{pH} 7.4$ ) containing either $0.01,0.03$, 0.08 or $0.5 \%(\mathrm{w} / \mathrm{w}) \mathrm{GA}$, respectively. The influence of pre-straining the samples during crosslinking on the mechanical properties of G-DSC samples was determined by applying a pre-strain of $60 \%$. The samples were hydrated before the pre-strain was applied and were either incubated in phosphate buffer $(\mathrm{pH}$ 7.4) for $1 \mathrm{~h}$ or crosslinked in $0.5 \%(\mathrm{w} / \mathrm{w}) \mathrm{GA}$ in phosphate buffer $(\mathrm{pH} \mathrm{7.4)}$ for $1 \mathrm{~h}$. All samples were washed and lyophilized as described above in the general procedure before tensile tests were performed. Strain was calculated as percentage change in length after fixation. The gauge length was defined relative to strained/fixed length.

Tensile test samples $(30.0 \times 6.0 \times 0.8 \mathrm{~mm})$ were cut using a blade knife and were hydrated for at least $30 \mathrm{~min}$ in phosphate buffered saline (PBS, 0.14 M $\mathrm{NaCl}, 0.01 \mathrm{M} \mathrm{Na}_{2} \mathrm{HPO}_{4}, 0.002 \mathrm{M} \mathrm{NaH}_{2} \mathrm{PO}_{4}, \mathrm{pH} 7.4$, NPBI, Emmercompascuum, the Netherlands) at room temperature. The width of the samples was measured in duplicate using callipers (Kanon, Tokyo, Japan) and the thickness was measured in triplicate using a spring-loaded type micrometer (Mitutoyo, Tokyo, Japan). An initial gauge length of $10 \mathrm{~mm}$ was used and during mechanical testing a crosshead speed of $5 \mathrm{~mm} / \mathrm{min}$ was applied until rupture of the test specimens occurred. The tensile strength, the elongation at alignment, the elongation at break, the low-strain 
modulus and the high-strain modulus of the sample were calculated from five independent measurements. Stress was calculated by the force divided by initial cross-sectional area.

\subsection{Microscopy}

Light microscopical techniques were used to study the morphology of samples pre-strained to $60 \%$ of their original length and incubated in either phosphate buffer $(\mathrm{pH} 7.4)$ or a $0.5 \%(\mathrm{w} / \mathrm{w}) \mathrm{GA}$ solution as described above. After allowing the samples to equilibrate during the post crosslinking washing procedure, they were fixed in a $2 \%(\mathrm{w} / \mathrm{w}) \mathrm{GA}$ solution in $0.1 \mathrm{M}$ phosphate buffer $(\mathrm{pH} 7.4)$ at $4{ }^{\circ} \mathrm{C}$ for $24 \mathrm{~h}$. Following fixation, the samples were dehydrated using graded alcohol/water solutions, embedded in glycol methacrylate and stained with toluidine blue [23].

\section{Results}

\subsection{Crosslinking}

Crosslinking of N-DSC samples with glutaraldehyde (GA) involves the reaction of the free amine groups of lysine or hydroxylysine amino acid residues of the polypeptide chains with the GA aldehyde groups. The first reaction that will take place (Scheme 1) is the formation of a Schiff base (III). Thereafter a large variety of subsequent reactions may be involved in the crosslinking of the material. Basically it might be expected that the intermediate III will react to give IV $(n=0)$. However, other reactions of III with GA are also possible. These reactions may lead to secondary or tertiary amines or pyridinium compounds. The extent of these reactions was measured by monitoring the decrease in primary amine group content of the DSC samples using a colorimetrical assay [19]. The degree of crosslinking of the samples was related to the shrinkage temperature $\left(T_{\mathrm{s}}\right)$ of the DSC samples [17].

To study whether the formed Schiff base group reacts with GA during crosslinking, the following experiments were performed. The Schiff bases formed by reaction of GA and N-DSC were subjected to hydrolysis after crosslinking by thorough washing with water. Schiff bases (imines) formed by reaction of an aliphatic amine and aldehyde can be easily hydrolysed at neutral $\mathrm{pH}$. Conjugated imines like V and VII are hydrolytically more stable but may be hydrolysed at acidic conditions. Control experiments using acid catalysis in the hydrolysis revealed no differences in amine group content compared to samples subjected to hydrolysis at neutral $\mathrm{pH}$. When only hydrolysable Schiff base containing crosslinks are formed the crosslinking should be completely reversible and the free amine group content of the washed samples should be equal to the initial free amine group content of the $\mathrm{N}$-DSC samples. However, in Fig. 1 it is shown that the initial free amine group content of 34/1000 amino acid residues decreased very fast and levelled off after $24 \mathrm{~h}$ to $5 / 1000$ amino acid residues for the washed G-DSC samples. This indicates that the hydrolysable Schiff bases present react with GA under the reaction conditions applied.

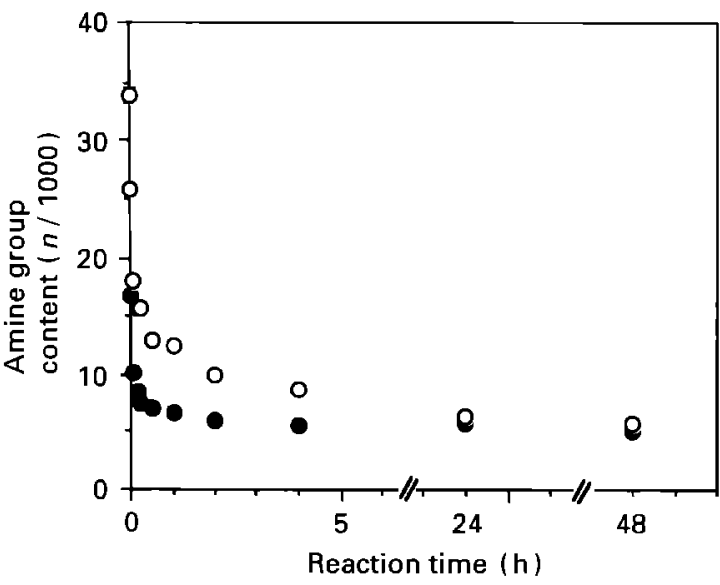

Figure 1 Primary amine group content of G-DSC samples as a function of reaction time. Before amine group determination Schiff bases formed during crosslinking were either hydrolysed by washing with distilled water and $4 \mathrm{M} \mathrm{NaCl}(\mathrm{O})$ or reacted with $\mathrm{NaBH}_{4}$ to secondary amines directly after crosslinking (O) (RT, pH $7.4,0.5 \%(w / w) G A, n=3)$.

In a second experiment the number of hydrolysable Schiff base groups present in the G-DSC samples as a function of crosslinking time was determined. The number of hydrolysable Schiff base groups present can be related to the difference between the free amine group content of G-DSC samples in which these Schiff bases are hydrolysed and the free amine group content of G-DSC samples in which the hydrolysable Schiff bases are converted to secondary amine groups by reduction with $\mathrm{NaBH}_{4}$ directly after crosslinking. The secondary amines generated after reduction do not interfere in the determination of the remaining primary amine content. In Fig. 1 it is shown that a faster decrease in free amine group content of the reduced G-DSC samples was observed compared to the samples subjected to hydrolysis. This shows that, especially in the initial stage of the crosslinking, hydrolysable Schiff base groups are present in the G-DSC samples. The difference in free amine group content of the G-DSC samples subjected to either hydrolysis or reduction decreases at longer reaction times. After a $24 \mathrm{~h}$ crosslinking time no difference in free amine group content was found. Obviously all hydrolysable Schiff bases react with GA in time to give hydrolytically stable compounds.

The $T_{\mathrm{s}}$ of G-DSC samples as a function of crosslinking time is presented in Fig. 2. During the initial stages of the crosslinking a fast increase in $T_{\mathrm{s}}$ is observed. Independent if samples were subjected to hydrolysis or to reduction, $T_{s}$ values of the samples appeared equal. This indicates that in all stages of the crosslinking the formed crosslinks do not contain hydrolysable Schiff base groups. A plateau value of $77^{\circ} \mathrm{C}$ for the shrinkage temperature was found after $1 \mathrm{~h}$ crosslinking. Longer reaction times did not result in an additional increase in $T_{s}$, although an additional decrease in amine group content was observed (Fig. 1).

Schiff base groups formed in the reaction of free amine groups with GA can be trapped if the crosslinking is carried out in the presence of $\mathrm{NaCNBH}_{3}$ (Scheme 2). In the presence of $\mathrm{NaCNBH}_{3}$ the Schiff base is rapidly converted to a secondary amine 


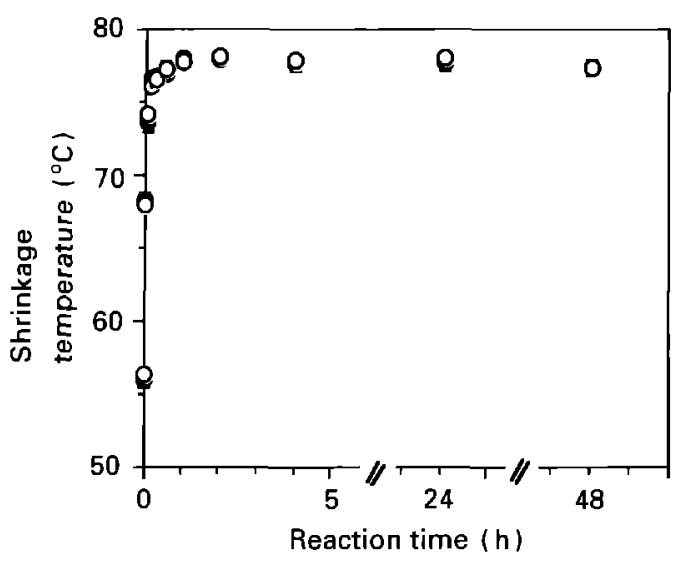

Figure 2 Shrinkage temperature of G-DSC samples as a function of reaction time. Before shrinkage temperature measurements Schiff bases formed during crosslinking were either hydrolysed with distilled water and $4 \mathrm{M} \mathrm{NaCl}(O)$ or reacted with $\mathrm{NaBH}_{4}$ to secondary amines directly after crosslinking (@) (RT, pH 7.4, 0.5\% (w/w) GA, $n=3$ ).

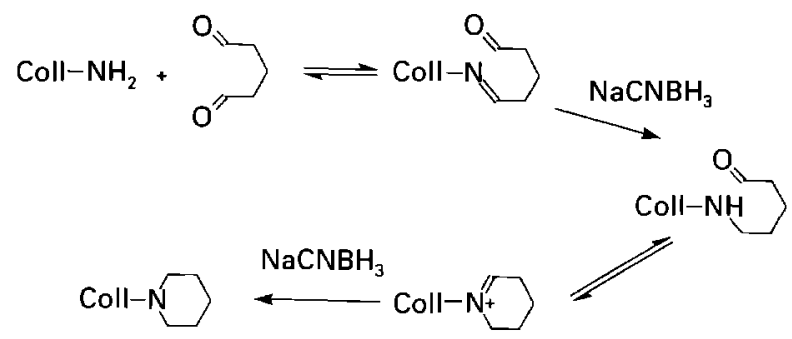

Scheme 2

followed by an intramolecular ring closing reaction with the formation of a six-membered ring. The cyclic six-membered imine is readily reduced by $\mathrm{NaCNBH}_{3}$ to give a piperidine ring [24]

The free amine group content as a function of reaction time using these reaction conditions is presented in Fig. 3. Within 5 min the free amine group content decreased from $34 / 1000$ amino acid residues to a plateau value of 5/1000 amino acid residues which showed that a rapid formation of Schiff bases occurs. No increase in $T_{\mathrm{s}}$ was found during reaction of GA with $\mathrm{N}$-DSC in the presence of $\mathrm{NaCNBH}_{3}$ (Fig. 4). The intramolecular cyclization reaction as well as the reduction steps obviously are much faster than the intermolecular reactions which would lead to the formation of crosslinks.

The free amine group content of N-DSC samples crosslinked with $\mathrm{GA}$ for $1 \mathrm{~h}$ as a function of the $\mathrm{pH}$ of the crosslinking solution is shown in Fig. 5. In general, the free amine group content was higher at lower $\mathrm{pH}$ values. Similar to the results obtained during the kinetic studies, a lower free amine group content was found for the G-DSC samples reacted with $\mathrm{NaBH}_{4}$ directly after the crosslinking compared to the washed G-DSC samples. The difference in free amine group content between both samples appeared to be somewhat larger at higher $\mathrm{pH}$ values.

During crosslinking, the $\mathrm{pH}$ of the crosslinking solution had only minor influence on the $T_{\mathrm{s}}$ as is shown in Fig. 6. Optimal crosslinking was obtained for $\mathrm{pH}$ values between 6 and 9 . No difference in $T_{\mathrm{s}}$ was

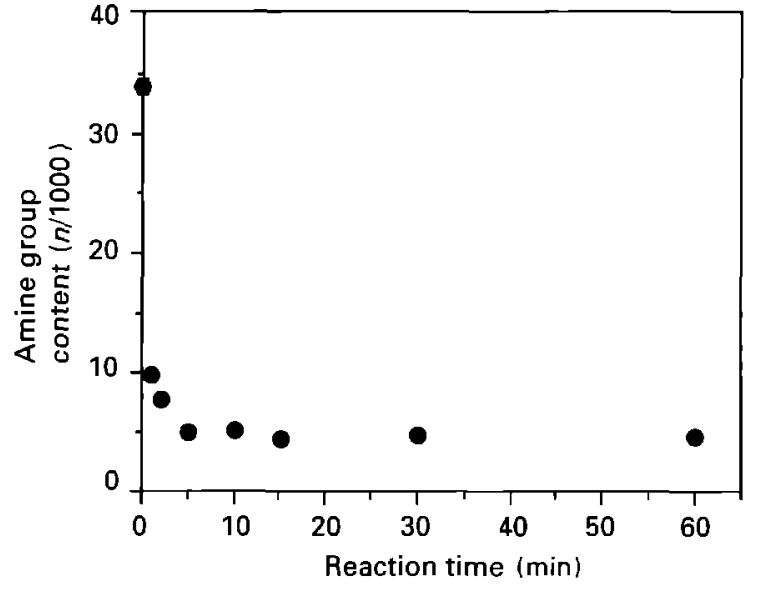

Figure 3 Primary amine group content of G-DSC samples as a function of reaction time during crosslinking of N-DSC with GA in the presence of $\mathrm{NaCNBH}_{3}(\mathrm{RT}, \mathrm{pH} 7.4,0.5 \%$ (w/w) GA, $1 \mathrm{mg} / \mathrm{ml}$ $\mathrm{NaCNBH}_{3}, n=3$ ).

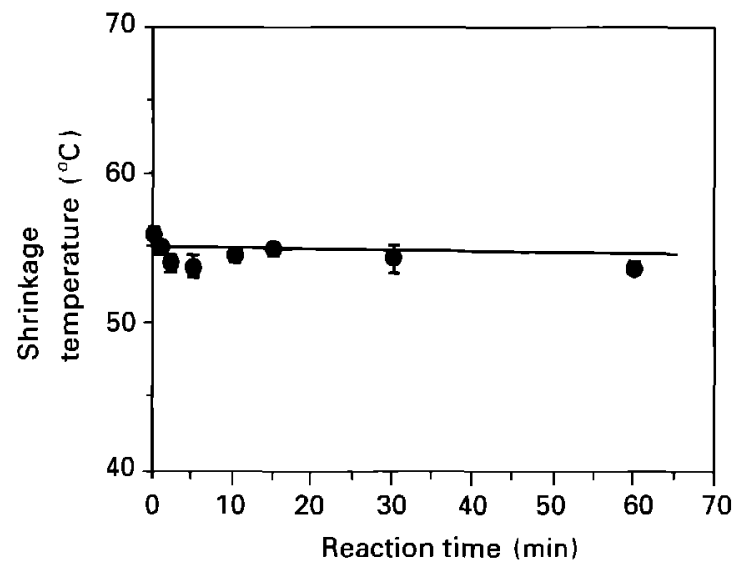

Figure 4 Shrinkage temperature of G-DSC samples as a function of reaction time during crosslinking of $\mathrm{N}$-DSC with $\mathrm{GA}$ in the presence of $\mathrm{NaCNBH}_{3}$ (RT, pH 7.4, 0.5\% (w/w) GA, $1 \mathrm{mg} / \mathrm{ml}$ $\mathrm{NaCNBH}_{3}, n=3$ ).

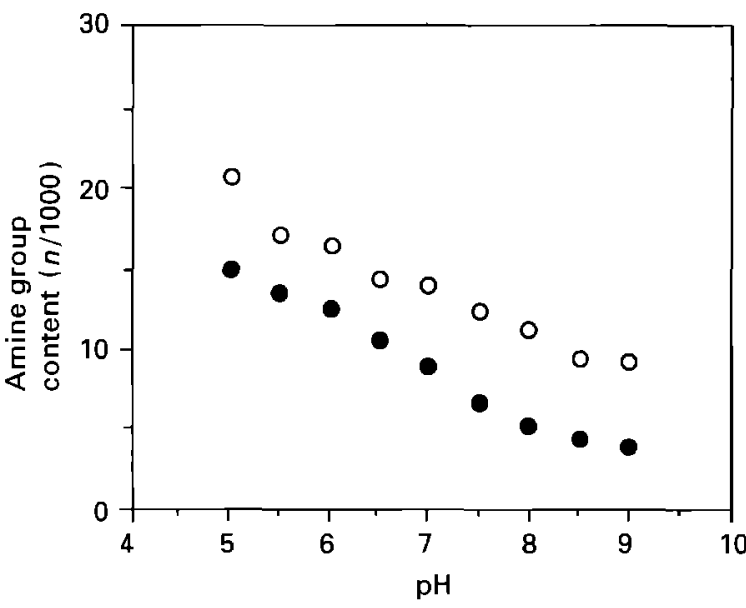

Figure 5 Primary amine group content of G-DSC samples as a function of $\mathrm{pH}$ during crosslinking. Before amine group determination Schiff bases formed during crosslinking were either hydrolysed by washing with distilled water and $4 \mathrm{M} \mathrm{NaCl}(\mathrm{O})$ or reacted with $\mathrm{NaBH}_{4}$ to secondary amines directly after crosslinking (O) (RT, 1 h, 0.5\% (w/w) GA, $n=3$ ). 


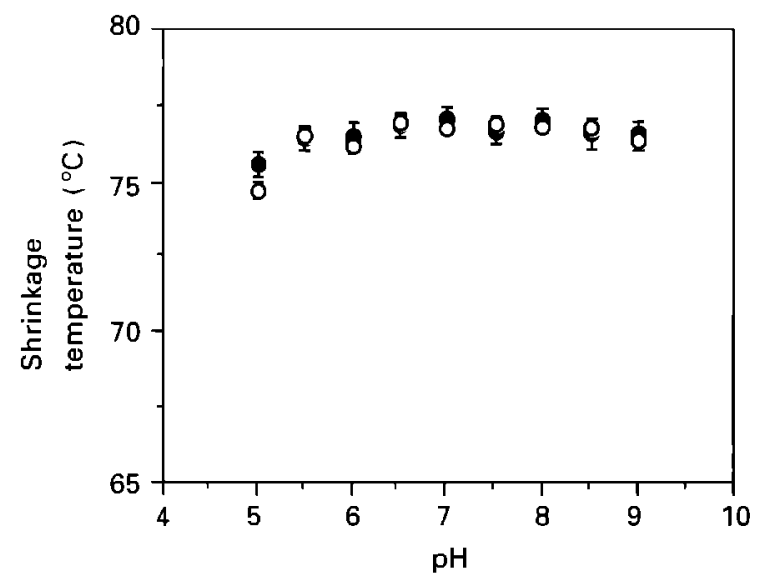

Figure 6 Shrinkage temperature of G-DSC samples as a function of $\mathrm{pH}$ during crosslinking. Before shrinkage temperature measurements Schiff bases formed during crosslinking were either hydrolysed by washing with distilled water and $4 \mathrm{M} \mathrm{NaCl}(O)$ or reacted with $\mathrm{NaBH}_{4}$ to secondary amines directly after crosslinking (ด) (RT, 1 h, 0.5\% (w/w) GA, $n=3$ )

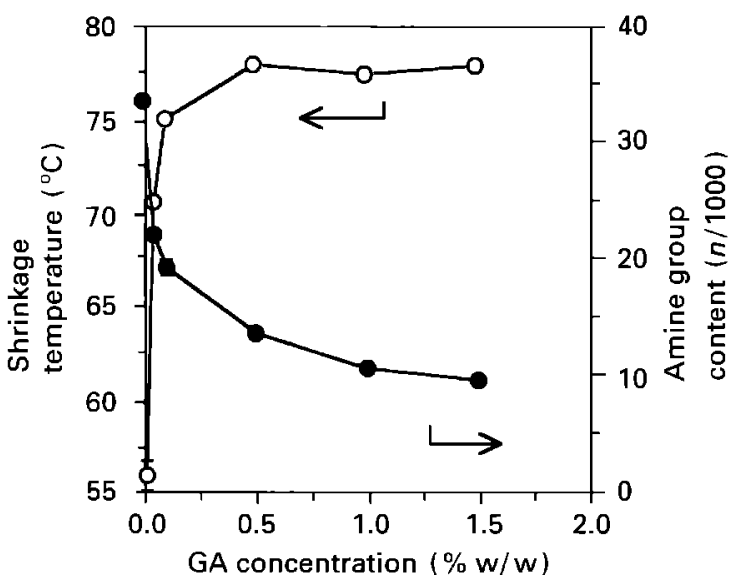

Figure 7 Shrinkage temperature $(O)$ and primary amine group content (๑) of G-DSC samples as a function of GA concentration used during crosslinking (RT, $1 \mathrm{~h}, \mathrm{pH} 7.4, n=3$ ).

found when G-DSC samples were either washed or reacted with $\mathrm{NaBH}_{4}$ after crosslinking.

The results obtained from the $T_{\mathrm{s}}$ measurements and the determination of the free amine group content after crosslinking N-DSC for $1 \mathrm{~h}$ at different GA concentrations are given in Fig. 7. The maximum $T_{\mathrm{s}}$ value of $77^{\circ} \mathrm{C}$ was obtained when a GA concentration of $0.5 \%(\mathrm{w} / \mathrm{w})$ was used while the free amine group content still decreased when concentrations higher than $0.5 \%(\mathrm{w} / \mathrm{w})$ were applied.

\subsection{Depletion measurements}

The average uptake of GA molecules per reacted amine group was determined from depletion measurements. When purified GA is reacted with 6-aminohexanoic acid the resulting UV spectrum shows an absorption maximum at $253 \mathrm{~nm}$. A linear calibration curve at this wavelength was obtained for GA solutions containing 0 to $1.0 \mathrm{mM}$ GA. Because aldol polymerization of glutaraldehyde in solution may occur under the crosslinking conditions used, the depletion of GA from the solution should be corrected. There- fore standard curves of GA solutions containing different amounts of aldol polymerization products were prepared. The aldol polymerization of purified GA solutions was enhanced by heating at $90^{\circ} \mathrm{C}$ and the amount of aldol polymers present was related to the purification index (PI), which is defined by the ratio between the absorbance at $235 \mathrm{~nm}$ resulting from the aldol polymers and the absorbance at $280 \mathrm{~nm}$ resulting from monomeric GA.

Glutaraldehyde solutions with PI values ranging from 0.3 to 35 were obtained. For comparison, the PI of a 1-year-old GA solution stored at $5-10^{\circ} \mathrm{C}$ was 5 . The slope of the standard curve as a function of the PI index of the GA solution is given in Fig. 8. Measurements at $235 \mathrm{~nm}$ revealed that the PI value does not influence the GA concentration measurements in the range studied. The average value of the slope of the standard curve at $235 \mathrm{~nm}$ was $0.79 \pm 0.02 \mathrm{~mm}^{-1}$

The PI index of the crosslinking solutions as a function of reaction time are given in Fig. 9. While initially no aldol polymers were present in the crosslinking solution aldol polymers are formed rapidly during crosslinking as indicated by the increase in PI. After $4 \mathrm{~h}$ a maximum PI value of 19 was determined. No further increase was observed for reaction times upto

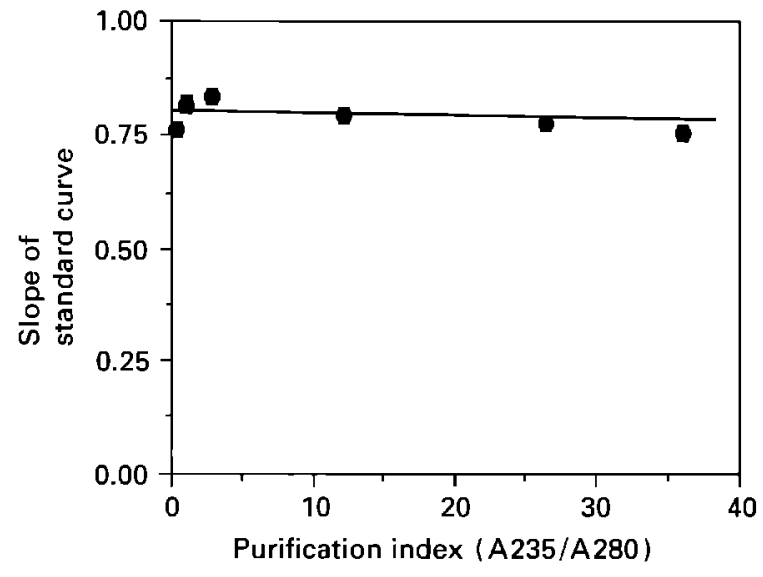

Figure 8 Slope of the standard curve of the colorimetrical GA assay at $253 \mathrm{~nm}$ as a function of the purification index of the GA solutions.

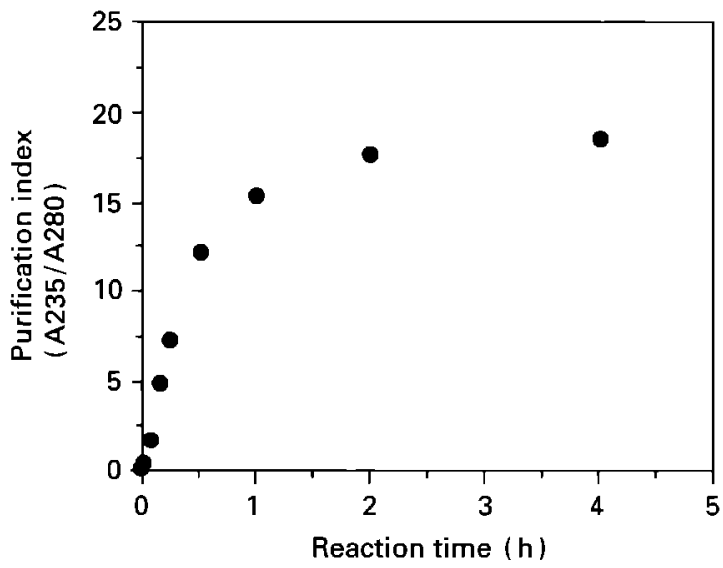

Figure 9 Purification index of GA solutions obtained after crosslinking of N-DSC with GA as a function of reaction time (RT, $\mathrm{pH}$ $7.4,0.5 \%(w / w) G A)$. 
$48 \mathrm{~h}$. The PI index of the crosslinking solution is also influenced by the $\mathrm{pH}$ used during crosslinking as is shown in Fig. 10. Higher PI values were found when crosslinking was performed at basic $\mathrm{pH}$ values. After crosslinking N-DSC for $1 \mathrm{~h}$ in $0.5 \%(\mathrm{w} / \mathrm{w})$ at $\mathrm{pH} 9$, the PI of the remaining GA solution was 15 .

In Fig. 11 the depletion of GA in the crosslinking solution is shown as a function of crosslinking time. After an initially fast decrease in GA concentration this decrease levelled off after $4 \mathrm{~h}$ crosslinking and a constant GA concentration of $0.33 \%(w / w)$ was observed after $24 \mathrm{~h}$ crosslinking. The average uptake of glutaraldehyde molecules per reacted amine group (mole/mole) is calculated from the depletion experiments and the decrease in amine group content. In order to have a correct value of the amount of amine groups present, the G-DSC samples were reacted with $\mathrm{NaBH}_{4}$ directly after crosslinking. The average uptake of glutaraldehyde molecules per reacted amine group as a function of crosslinking time is presented in Fig. 12. After an initially fast increase in the number of GA molecules reacted per reacted amine group this increase levelled off after $4 \mathrm{~h}$ to approximately $3 \mathrm{GA}$ molecules per reacted amine group.

According to a similar procedure to that described above, the average GA uptake per reacted amine

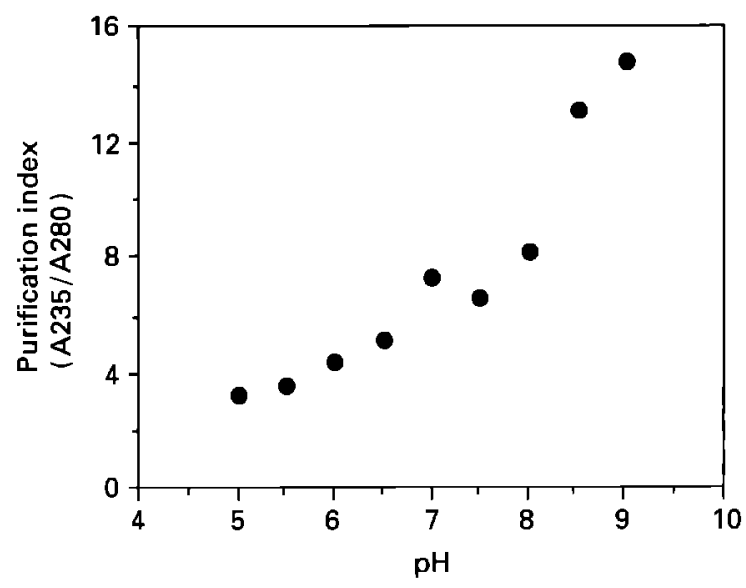

Figure 10 Purification index of GA solutions obtained after crosslinking of N-DSC with GA as a function of $\mathrm{pH}(\mathrm{RT}, 1 \mathrm{~h}, 0.5 \%(\mathrm{w} / \mathrm{w})$ GA).

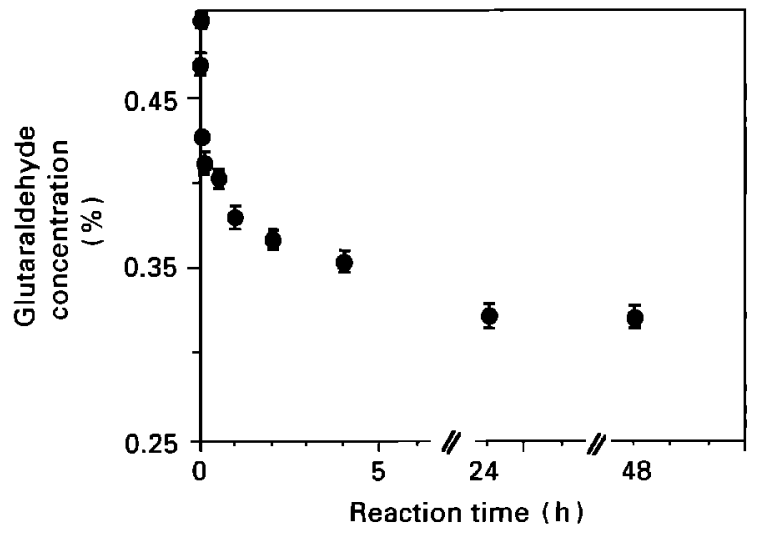

Figure 11 Depletion of GA from the crosslinking solution as a function of reaction time (RT, pH 7.4, 0.5\% (w/w) GA, $n=5$, \pm s.d.). group is calculated for samples crosslinked for $1 \mathrm{~h}$ at different $\mathrm{pH}$ values (Fig. 13). No significant difference in $\mathrm{GA}$ uptake was found at $\mathrm{pH}$ values in between 5 and 9 after $1 \mathrm{~h}$ crosslinking. On an average, $2 \mathrm{GA}$ molecules had reacted with one amine group under these conditions.

During the depletion measurements, adsorption of GA to the DSC matrix could result in a significant depletion of GA from the crosslinking solution. To check this, G-DSC samples crosslinked for $24 \mathrm{~h}$ with GA and thoroughly washed, having no amine groups available for further reaction with GA molecules (Fig. 1), were incubated in a fresh $0.5 \%(\mathrm{w} / \mathrm{w}) \mathrm{GA}$ solution. No change in GA concentration could be detected during a $6 \mathrm{~h}$ incubation period showing that no significant adsorption of GA to the DSC matrix had occurred.

\subsection{Mechanical properties}

A typical stress-strain curve for DSC is given in Fig. 14. This curve can be divided into four distinctive parts. Initially the fibre-bundles are randomly

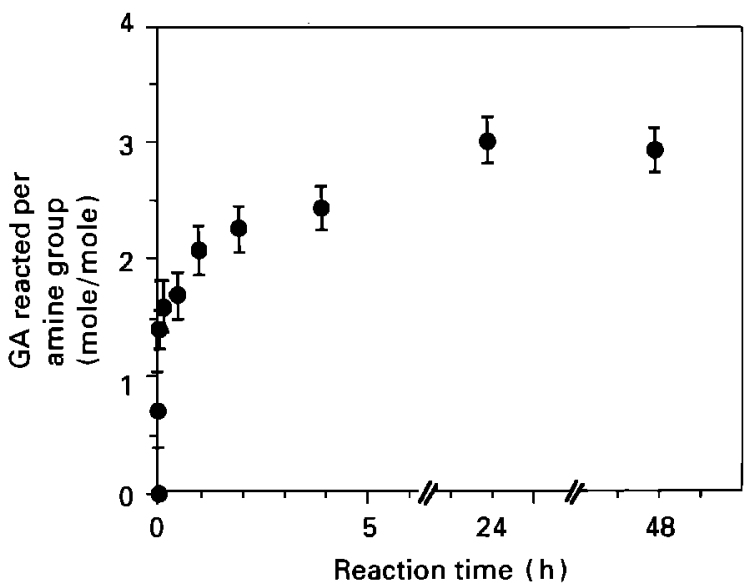

Figure 12 Average uptake of GA molecules per reacted amine group as a function of crosslinking time. Values are calculated from the amine group contents of G-DSC reacted with $\mathrm{NaBH}_{4}$ directly after crosslinking (Fig. 1) and the depletion of the GA solution (Fig. 11) (RT, pH 7.4, 0.5\% (w/w) GA).

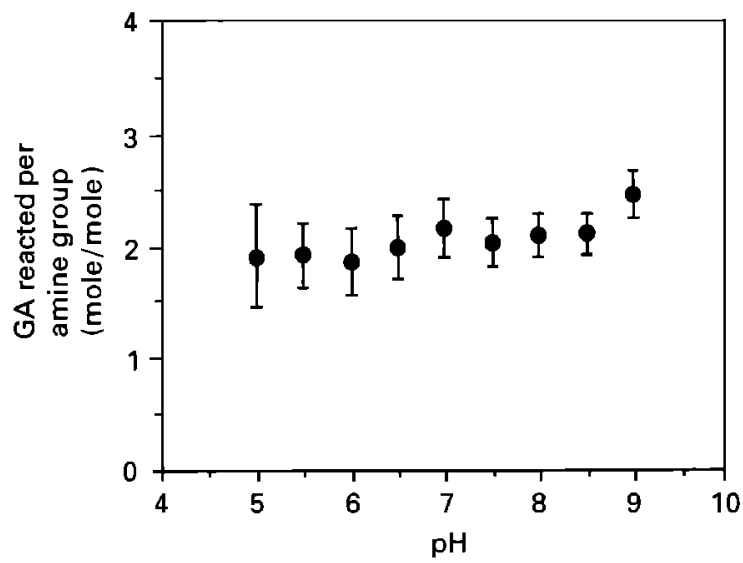

Figure 13 Average uptake of $\mathrm{GA}$ molecules per reacted amine group as a function of the $\mathrm{pH}$ during crosslinking ( $\mathrm{RT}, 1 \mathrm{~h}, 0.5 \%$ (w/w) GA). 
orientated and only small stresses are necessary to straighten the fibre-bundles (part I). The resistance of the network against straightening is measured as the low-strain modulus and the initial orientation of the fibre-bundles can be related to the elongation at alignment. As more and more fibre-bundles become taut, an increase in modulus is observed (part II). The linear part of the stress-strain curve at high strains (part III) is referred to as the high-strain modulus. At a sufficient stress, the material starts to yield and finally breaks (part IV). The tensile strength is the maximum stress applied divided by the cross-sectional area, the elongation at the point where the fibre-bundles fail is referred to as the elongation at break.

The mechanical properties of N-DSC and G-DSC samples as a function of $T_{\mathrm{s}}$ are presented in Table I. No significant differences in tensile strength and elon-

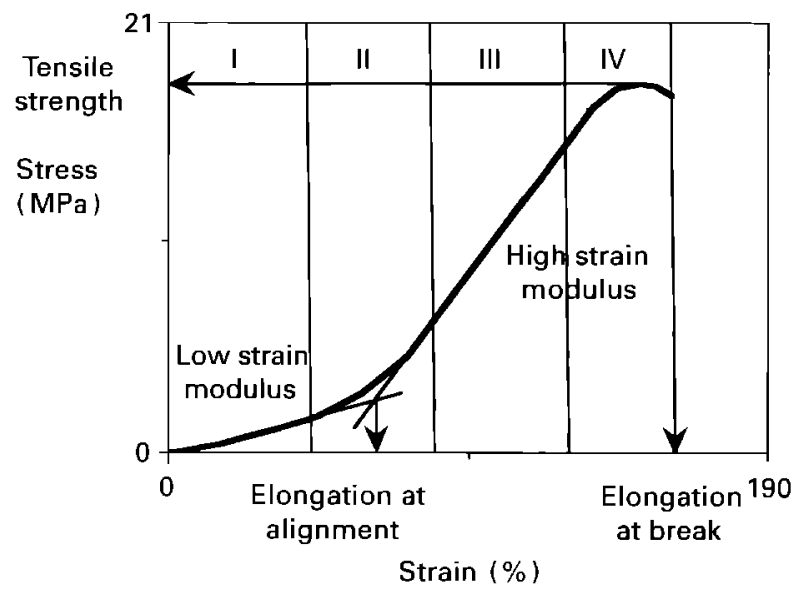

Figure 14 Typical stress-strain curve for non-crosslinked and crosslinked dermal sheep collagen. gation at alignment as a function of $T_{\mathrm{s}}$ were found. For N-DSC and all G-DSC samples an average tensile strength of $21 \mathrm{MPa}$ and an average elongation at alignment of $60 \%$ was determined. The elongation at break was $125 \%$ for N-DSC and $158 \%$ for G-DSC with a $T_{\mathrm{s}}$ of $62^{\circ} \mathrm{C}$. Slightly lower values of the elongation at break were observed for G-DSC samples having higher $T_{s}$ values. The low-strain modulus of N-DSC (1.7 MPa) increased with increasing $T_{\mathrm{s}}$ value to $3.3 \mathrm{MPa}$ for G-DSC having a $T_{\mathrm{s}}$ of $66^{\circ} \mathrm{C}$. Similar low-strain moduli were found for G-DSC having a $T_{\mathrm{s}}$ of $73.5^{\circ} \mathrm{C}(3.8 \mathrm{MPa})$ and G-DSC having a $T_{\mathrm{s}}$ of $78.3^{\circ} \mathrm{C}(3.5 \mathrm{MPa})$. The high-strain modulus decreased with increasing $T_{\mathrm{s}}$ value from $33 \mathrm{MPa}$ for N-DSC to an average value of $23 \mathrm{MPa}$ for G-DSC samples.

The influence of applying pre-strain during crosslinking on the mechanical properties of the resulting G-DSC samples is presented in Table II. After the pre-strain treatment, both the non-crosslinked and the crosslinked samples were allowed to equilibrate for $2 \mathrm{~h}$ before stress-strain measurements were performed. Control N-DSC samples (initial length $2 \mathrm{~cm}$ ), pre-strained for $1 \mathrm{~h}$ to $60 \%$ of the initial length $(3.2 \mathrm{~cm})$ in phosphate buffer $(\mathrm{pH} 7.4)$ measured $2.5 \mathrm{~cm}$ after equilibration. These samples showed a decrease in tensile strength from $20 \mathrm{MPa}$ to $16 \mathrm{MPa}$, a decrease in elongation at alignment from $62 \%$ to $46 \%$ and a decrease in elongation at break from $167 \%$ to $136 \%$ compared to non-pre-strained N-DSC. No significant differences were found for the low- and high-strain modulus. When N-DSC samples were subjected to a $60 \%$ pre-strain during crosslinking with $\mathrm{GA}$, a tensile strength of $27 \mathrm{MPa}$ was found for the resulting G-DSC samples. Furthermore the elongation at break decreased from $136 \%$ to $50 \%$ and a large increase in

TA B LE I Mechanical properties of N-DSC and G-DSC samples

\begin{tabular}{lllllll}
\hline Sample & $\begin{array}{l}\text { Shrinkage } \\
\text { temperalure } \\
(\mathrm{C})\end{array}$ & $\begin{array}{l}\text { Tensile } \\
\text { strength } \\
\text { (MPa) }\end{array}$ & $\begin{array}{l}\text { Elongation } \\
\text { at alignment } \\
(\%)\end{array}$ & $\begin{array}{l}\text { Elongation } \\
\text { at break } \\
(\%)\end{array}$ & $\begin{array}{l}\text { Low-strain } \\
\text { modulus } \\
\text { (MPa) }\end{array}$ & $\begin{array}{l}\text { High-strain } \\
\text { modulus } \\
\text { (MPa) }\end{array}$ \\
\hline N-DSC $^{\mathrm{a}}$ & $56.0 \pm 0.3$ & $21.5 \pm 1.3$ & $58 \pm 5$ & $125 \pm 7$ & $1.7 \pm 0.4$ & $32.7 \pm 2.0$ \\
G-DSC $^{\text {b }}$ & $61.6 \pm 0.3$ & $19.4 \pm 1.2$ & $70 \pm 5$ & $158 \pm 4$ & $1.8 \pm 0.1$ & $23.1 \pm 1.2$ \\
& $66.4 \pm 0.4$ & $22.1 \pm 1.2$ & $60 \pm 5$ & $150 \pm 9$ & $3.3 \pm 0.2$ & $24.2 \pm 1.6$ \\
& $73.5 \pm 0.4$ & $20.8 \pm 2.0$ & $60 \pm 6$ & $148 \pm 5$ & $3.8 \pm 0.1$ & $22.8 \pm 2.0$ \\
& $78.3 \pm 0.3$ & $21.3 \pm 1.5$ & $65 \pm 4$ & $145 \pm 5$ & $3.5 \pm 0.3$ & $21.0 \pm 1.0$ \\
\hline
\end{tabular}

"Non-crosslinked DSC,

${ }^{\mathrm{h}}$ Glutaraldehyde crosslinked DSC. N-DSC samples were crosslinked for $1 \mathrm{~h}$ in phosphate buffer ( $\mathrm{pH} 7.4$ ) containing $0.01,0.03,0.08$ or $0.5 \%$ $(w / w) G A$, respectively. Mechanical properties were averaged from five measurements ( \pm s.d.).

TA B LE II Effect of pre-strain on the mechanical properties of N-DSC and G-DSC

\begin{tabular}{lllllll}
\hline Sample & $\begin{array}{l}\text { Pre-strain } \\
\text { applied } \\
(\%)\end{array}$ & $\begin{array}{l}\text { Tensile } \\
\text { strength } \\
(\mathrm{MPa})\end{array}$ & $\begin{array}{l}\text { Elongation } \\
\text { at alignment } \\
(\%)\end{array}$ & $\begin{array}{l}\text { Elongation } \\
\text { at break } \\
(\%)\end{array}$ & $\begin{array}{l}\text { Low-strain } \\
\text { modulus } \\
\text { (MPa) }\end{array}$ & $\begin{array}{l}\text { High-strain } \\
\text { modulus } \\
\text { (MPa) }\end{array}$ \\
\hline $\mathrm{N}-\mathrm{DSC} \mathrm{C}^{\mathrm{a}}$ & 0 & $19.8 \pm 1.2$ & $62 \pm 6$ & $167 \pm 18$ & $1.7 \pm 0.3$ & $21.7 \pm 2.4$ \\
$\mathrm{~N}-\mathrm{DSC}^{\mathrm{b}}$ & 60 & $15.8 \pm 0.6$ & $46 \pm 4$ & $136 \pm 9$ & $2.4 \pm 0.5$ & $19.9 \pm 1.8$ \\
$\mathrm{G}^{\mathrm{D} D S C}$ & 60 & $26.6 \pm 2.0$ & - & $50 \pm 2$ & - & $59.9 \pm 4.9$ \\
\hline
\end{tabular}

\footnotetext{
"Non-crosslinked DSC,

${ }^{\natural}$ Glutaraldehyde crosslinked DSC. N-DSC samples were crosslinked under pre-strain conditions for $1 \mathrm{~h}$ in phosphate buffer (pH 7.4) containing $0.5 \%(\mathrm{w} / \mathrm{w}) \mathrm{GA}$. Mechanical properties were averaged from five measurements ( \pm s.d.).
} 
high strain modulus from $20 \mathrm{MPa}$ to $60 \mathrm{MPa}$ was found. In these samples most of the deformation implemented during pre-straining was fixed since these samples had a length of $3.1 \mathrm{~cm}$ after equilibration. The degree of crosslinking of N-DSC samples crosslinked with GA using pre-strain conditions was similar to G-DSC samples crosslinked without applying the prestrain. In both cases $T_{\mathrm{s}}$ values of $78^{\circ} \mathrm{C}$ were determined.

\subsection{Microscopy}

The fixation of the G-DSC samples crosslinked using pre-strain conditions was studied using light microcopy (LM). In Fig. 15a and 15b LM micrographs of the pre-strained N-DSC control samples are presented. The morphology of the samples appeared identical when these samples were cut either transverse (Fig. 15a) or parallel (Fig. 15b) to the pre-strain direction. A similar morphology was observed for the G-DSC samples crosslinked using pre-strain conditions as viewed transversely to the pre-strain direction (Fig. 16a). In contrast, the morphology of these samples parallel to the pre-strain direction (Fig. 16b) revealed many longitudinally cut fibre bundles indicating the fixation of the structure of these samples during crosslinking.

\section{Discussion}

Glutaraldehyde (GA) has shown to be an effective crosslinking agent for the stabilization of collagenbased biomaterials. Up to now several studies towards the mechanism of GA crosslinking have been reported. For this purpose both model reactions of GA with 6-amino-hexanoic acid or glycine $[4,9]$ and reactions with proteins $[8,13,25]$ have been studied. These studies revealed that GA crosslinking is a very complicated process, resulting in the formation of a large variety of possible crosslinking entities (Scheme 1). Although isolation and characterization of these products would seem to be the most direct approach to understand the mechanism of GA crosslinking, the complex nature of the reactions involved suggest the difficulty of this approach.

In collagen and other proteins, GA reacts with the free amine groups of lysine or hydroxylysine amino acid residues of the polypeptide chains to form Schiff base intermediates. The Schiff base III as presented in Scheme $1[4,6,7]$ is regarded as the central intermediate from which several subsequent reactions may occur before a crosslink is formed [10]. The imine III is an unstable intermediate and hydrolysis to the starting materials can easily occur in water. It may be expected that those crosslinks which are formed after an intramolecular reaction of the remaining aldehyde group with another amine group and thus contain
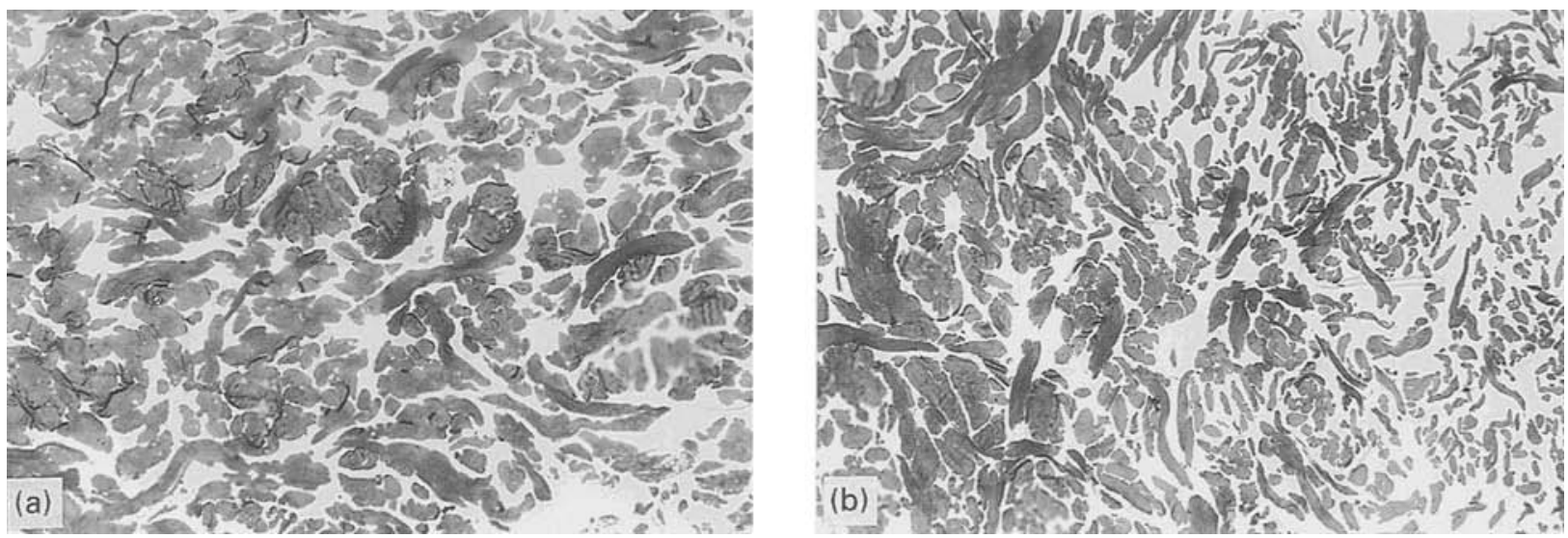

Figure 15 LM micrographs of the morphology of pre-strained N-DSC control samples cut either transverse (a) or parallel to the pre-strain direction. Magnification 10x.
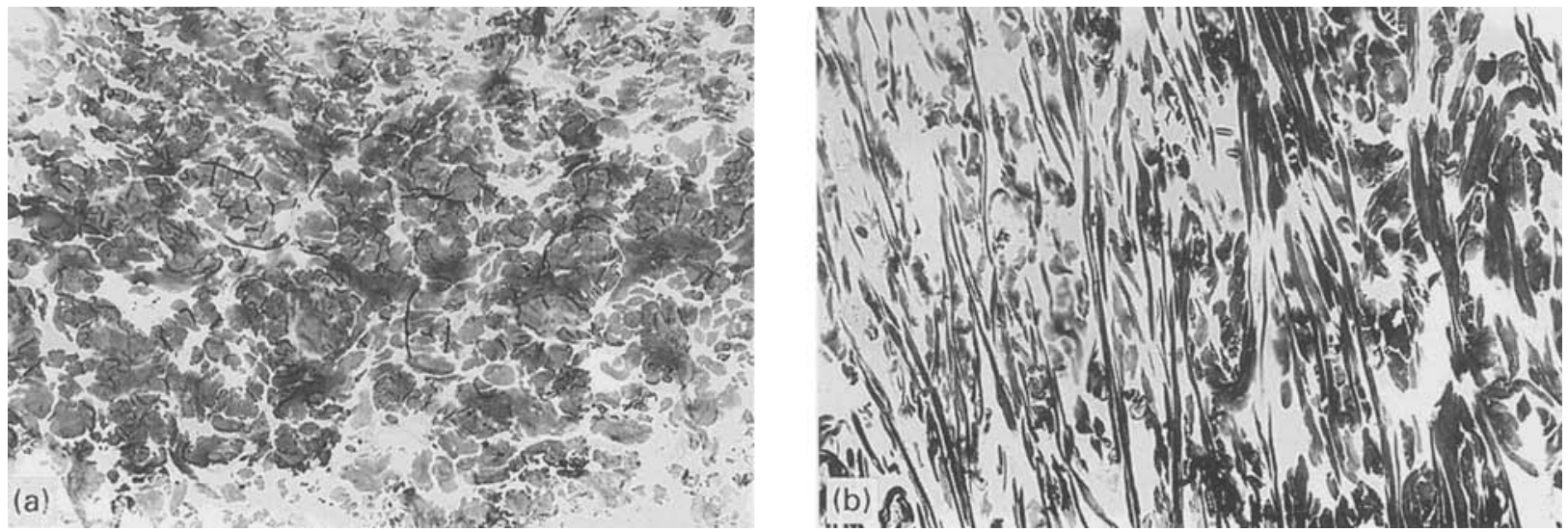

Figure I6 LM micrographs of the morphology of G-DSC samples crosslinked using pre-strain conditions cut either transverse (a) or parallel to the pre-strain direction. Magnification 10x. 
isolated imine groups (as in IV) are hydrolytically unstable. The intermediate III may react further in different ways. In the aqueous environment, formation of the cyclic aminal XII is possible. Crosslinks may be formed after reaction of XII with glutaraldehyde and water to give XIII. Like most acetals and animals these crosslinks may be regarded as easily hydrolysed in the presence of dilute acids.

Intermediate III may also react with glutaraldehyde in two other ways. First, in an aldol-type condensation reaction, compound $\mathrm{V}$ is the resulting product. Second, by reaction of III in a Mannich type reaction the secondary amine VIII is formed. Whereas VIII would be a stable compound the $\alpha$ - $\beta$-unsaturated imine $\mathrm{V}$ may still be hydrolysable, especially under acidic conditions. The same considerations apply to structures VI and VII, which may also be hydrolysed in an acidic environment.

In a series of papers Hardy et al. [9, 13] described the reaction of glutaraldehyde with the protein ovalbumine and model compounds 6-aminohexanoic acid and $\alpha$-N-acetyl-lysine. Analysis of acid hydrolysates of crosslinked ovalbumine by ${ }^{1} \mathrm{H}-\mathrm{NMR}$ revealed the presence of anabilysine (as present in XI). The structure of this compound was confirmed by synthesis. Reaction of GA with the model compounds revealed the presence of a product, amongst at least twelve other products, analogous to structure $\mathrm{X}$ and was confirmed by ${ }^{1} \mathrm{H}-\mathrm{NMR}$ data. The reactions described involve the oxidation of a dihydropyridine to a pyridinium compound. More recently the oxidation was confirmed by the rapid uptake of oxygen during glutaraldehyde fixation of tissue [12].

Due to reaction of $\mathrm{GA}$ with non-crosslinked dermal sheep collagen (DSC) samples the free amine group content of these samples, which is determined by measuring the primary amines present, decreases. As discussed above reaction of GA with free amine groups can result in the formation of either Schiff base groups, secondary or tertiary amine groups or pyridinium compounds. Assuming that Schiff base containing crosslinks have been formed the crosslinking should be completely reversible upon hydrolysis of the Schiff bases and the $T_{\mathrm{s}}$ and the free amine group content of the washed samples should be equal to the values of the starting non-crosslinked DSC samples (N-DSC). However, both a decrease in free amine group content (Fig. 1) and an increase in $T_{\mathrm{s}}$ (Fig. 2) was observed for GA crosslinked DSC samples (G-DSC) subjected to a washing procedure. No further decrease in free amine group content was found when these samples were subjected to an acidic hydrolysis procedure. Obviously further reaction of Schiff bases with GA does take place during the crosslinking process.

Additional evidence for the reaction of the Schiff bases with GA was found when the number of primary amine groups present in the G-DSC samples was monitored as a function of crosslinking time. The primary amine group content of G-DSC samples subjected either to hydrolysis or to conditions in which the Schiff bases are converted to secundary amines by reduction with $\mathrm{NaBH}_{4}$ was determined. The difference between the values is a measure of the number of hydrolysable Schiff base intermediates present in the samples at each time. In Fig. 1 it is shown that in the initial phase of the crosslinking a large difference in primary amine group content is observed when the two procedures are used.

The much higher values of the primary amine group content in the early stages of the reaction is the result of the presence of a high percentage of Schiff bases which are hydrolysed during the washing procedure. At reaction times over $24 \mathrm{~h}$ no difference in primary amine group content is observed anymore. This means that all initially formed Schiff bases have reacted in time and the hydrolysis is blocked. Since no difference in $T_{s}$ was found between the $\mathrm{NaBH}_{4}$-treated and washed G-DSC samples (Fig. 2) this implies that only after stabilization of the initially formed hydrolysable Schiff base, crosslinks are introduced in the DSC matrix.

In the crosslinking a sequence of reactions has taken place in which most likely structure VIII is involved as an intermediate. Only when the aldol condensation reaction to give $\mathrm{V}$ is followed by rapid reactions to give hydrolytically stable crosslinks a contribution of pathways via intermediate structures VI and VII to the overall crosslinking cannot be excluded. The elucidation of structure XI as one of the crosslinks present after reaction of ovalbumine with GA implies that either the intermediate $V$ may be regarded a hydrolytically stable imine or that the subsequent reactions to give XI are very fast.

The rate at which Schiff bases are formed during reaction of GA with $\mathrm{N}$-DSC samples was studied using the reducing agent $\mathrm{NaCNBH}_{3}$. In the presence of $\mathrm{NaCNBH}_{3}$ the Schiff base is rapidly converted to a secondary amine followed by an intramolecular ring closing reaction with the formation of a six-membered ring (Scheme 2). The cyclic six-membered imine is readily reduced by $\mathrm{NaCNBH}_{3}$ to give a piperidine ring [24]. Within $5 \mathrm{~min}$ the reaction had gone to completion (Fig. 3) showing that both the formation of the imine bond and reduction are fast processes. The reaction pathway given in Scheme 2 implies that no crosslinking should take place. This is confirmed by the $T_{s}$ measurements (Fig 4) which showed that $T_{\mathrm{s}}$ remained unchanged independent of the reaction time. Not all amine groups are available for reaction with GA and a plateau value of 5/1000 amino acid residues is reached after crosslinking for $24 \mathrm{~h}$. Similar results have been reported by Bowes et al. [26] who found that from the available 32-33 mmoles of amine groups in collagen only $26-27$ mmoles are available for reaction with GA.

Although the maximum increase in $T_{\mathrm{s}}$ was obtained within $1 \mathrm{~h}$ crosslinking, longer reaction times still decreased the free amine group content of the G-DSC samples (Fig. 2, washed samples). Similar results were observed when higher GA concentrations were used during crosslinking (Fig. 7). The decrease in free amine group content as a function of increase in $T_{\mathrm{s}}$ (Fig. 17) shows a linear relationship up to a $T_{\mathrm{s}}$ of $78^{\circ} \mathrm{C}$. At longer reaction times (or higher GA concentrations) a decrease in free amine group content at a constant $T_{\mathrm{s}}$ value was found. Glutaraldehyde still is able to react with free amine groups but the formation of additional 


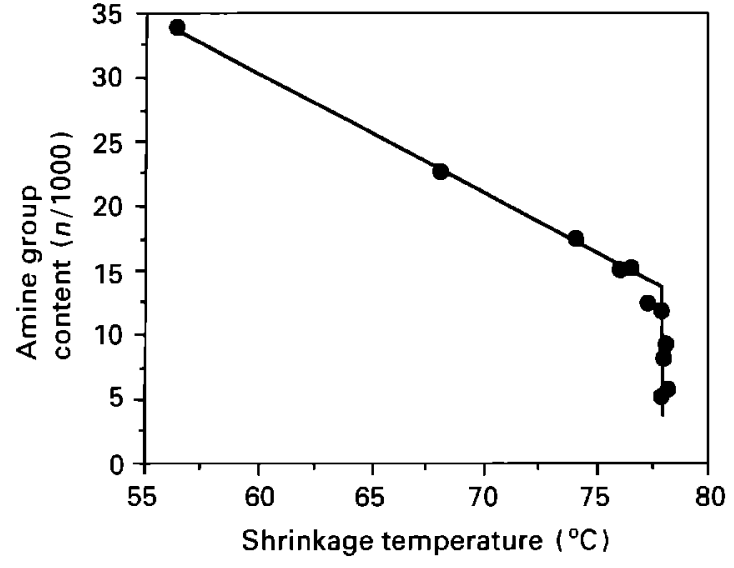

Figure 17 Free amine group content as a function of shrinkage temperature of G-DSC samples. Schiff bases formed during crosslinking were hydrolysed by washing with distilled water and $4 \mathrm{M}$ $\mathrm{NaCl}$ before amine group determination and $T_{s}$ measurements.

crosslinks seems to be inhibited. Only pendant-GArelated molecules are incorporated in the DSC matrix.

However, this does not imply that only at longer reaction times or higher $\mathrm{GA}$ concentrations are pendant-GA-related molecules introduced. Already at the start of the crosslinking these pendant GA molecules may be formed. The results presented in Figs 5 and 6 (washed samples) show that the free amine group content of G-DSC samples is dependent on the $\mathrm{pH}$ used during crosslinking. Lower free amine group contents were observed for samples crosslinked at higher $\mathrm{pH}$ values. Because all samples had similar degrees of crosslinking this indicates that more pendant molecules are introduced into the DSC matrix at higher $\mathrm{pH}$ values.

Since Schiff bases are more stable at basic $\mathrm{pH}$ values $[9,11]$, on the average a larger number of Schiff base groups will be present in the G-DSC samples during crosslinking at basic $\mathrm{pH}$ values. It is likely that this will have a beneficial effect on the subsequent reaction of the Schiff bases with GA which can result in the formation of, for instance, VIII. It is possible that not all of the formed VIII will be involved in the formation of a crosslink (IX or X) but will also result in the formation of pendant molecules. Because the free amine group content of samples with similar $T_{\mathrm{s}}$ values is dependent on the $\mathrm{pH}$ used during crosslinking, it is evident that the $\mathrm{pH}$ will also influence the slope of the linear part of the relationship between the decrease in free amine group content and the increase in $T_{\mathrm{s}}$.

Although it is suggested that crosslinking of collagen at basic $\mathrm{pH}$ values will result in a more effective crosslinking of the material [14] the results obtained in this study indicate that crosslinking at acidic $\mathrm{pH}$ values has to be preferred. First, no large differences in $T_{\mathrm{s}}$ values were observed when varying the $\mathrm{pH}$ of the crosslinking solution between 5 and 9, indicating that all materials had similar degrees of crosslinking. Second, as discussed above the samples crosslinked at acidic $\mathrm{pH}$ values have less pendant GA molecules introduced into the material. This is expected to be favourable because the toxicity of G-DSC has been related to the release of glutaraldehyde-related molecules from the DSC matrix.
The maximum increase in the $T_{\mathrm{s}}$ of the N-DSC samples after crosslinking with GA was $22-23^{\circ} \mathrm{C}$. Similar results have been reported for GA crosslinking of kangaroo tail tendon [27], lyophilized dermal sheep collagen [28] and pericardial tissue [29].

Previously, reactions of GA with the model compounds glycine and 6-aminohexanoic acid have been used to study the mechanism of crosslinking [4]. Whereas low molecular weight compounds are formed at low GA concentrations, compounds with a molecular weight up to 4000 have been observed when high concentrations of GA were used. In order to determine if high molecular weight crosslinks are formed under the crosslinking conditions used, GA depletion experiments were carried out. Prior to the depletion measurements the influence of aldol polymerization products on the GA concentration measurements of the crosslinking solution was determined. Therefore GA solutions with different amounts of aldol polymers present were prepared. The purification index (PI), the ratio between the UV absorbance at $235 \mathrm{~nm}$ (aldol polymer) and $280 \mathrm{~nm}$ (monomer), was used for analysis. Solutions having PI values between 0.4 and 35 , and thus containing different amounts of aldol polymers, were obtained. Within this range, accurate measurements of the GA concentration by colorimetric assay appeared possible.

During crosslinking of N-DSC samples with GA, aldol condensation polymers were formed in the GA solution (Fig. 9). These polymers may be formed as a result of initiation with a primary amine group [4] which appeared to be promoted by using basic $\mathrm{pH}$ values during crosslinking (Fig. 10). This increase in PI was not observed for GA solutions which did not contain N-DSC samples. Using the molar extinction coefficients of two model compounds, acetaldehyde $\left(7.51 \mathrm{~mol}^{-1} \mathrm{~cm}^{-1}\right.$ at $\left.280 \mathrm{~nm}\right)$ and crotonaldehyde $\left(155751 \mathrm{~mol}^{-1} \mathrm{~cm}^{-1}\right.$ at $\left.220 \mathrm{~nm}\right)$, the concentration of $\alpha-\beta$-unsaturated aldehyde groups may be calculated as being only $1.7 \%(\mathrm{~mol} / \mathrm{mol})$ of the total aldehyde content for GA solutions with a PI of 35 [30]. This implies that only a low amount of aldol polymers is formed in the solution during crosslinking which does not suggest a significant contribution of these molecules to the crosslinking.

From the depletion measurements it was found that the depletion of GA from the crosslinking solution was fast in the initial stage of the crosslinking (Fig. 11). The number of amine groups that had reacted was determined by subjecting the DSC samples at the same time intervals to a $\mathrm{NaBH}_{4}$ solution. At reaction times over $24 \mathrm{~h}$ no Schiff bases are present in the material (Fig. 1) and an average of $3 \mathrm{GA}$ molecules per reacted amine group is observed. This limited GA uptake per reacted amine group is in contrast with the mechanism for the GA crosslinking proposed by Nimni et al. $[1,8,25]$ who suggested that crosslinking of collagen with GA involves the formation of large polymeric GA networks. The $\mathrm{pH}$ has no significant influence on the average GA uptake per reacted amine group (Fig. 13) indicating that the reactions involved during crosslinking are not influenced by $\mathrm{pH}$.

Since the crosslinks introduced in the DSC matrix do not contain hydrolysable Schiff base groups, 
structures IX, X, XI or reaction products of e.g. VII with GA will be involved (Scheme 1). Furthermore, since the average uptake of GA per amine group is approximately 3 , the formation of large polymeric networks becomes unlikely. Either a large fraction of IX or reaction products of VII with low values of $n$ or a small fraction of these compounds with high values of $n$ are expected. It cannot be excluded that also other crosslinks are formed which are not depicted in Scheme 1 since the complete mechanism of the GA crosslinking is still not understood.

The behaviour of fibrous collagens like DSC during stress-strain measurements is only poorly understood. Since DSC is a random network of fibre bundles which are highly structured aggregates of fibres and fibrils, respectively, its mechanical properties are not only dependent on the mechanical properties of the individual fibre bundles but also on their spatial arrangement. Furthermore, the mode of interweaving of fibres from one bundle to another is very important for the structural stability of the three-dimensional fibre bundle network [31, 32, 33]. The stress-strain measurements described in this paper were always performed with fully hydrated samples (phosphate bufferedsaline). The hydration was performed to undo the changes in mechanical properties due to lyophilization.

In Fig. 14 a typical stress-strain curve for DSC is given which can be divided into a low-strain area (I), a transition area (II), a high-strain area (II) and a failure area (IV). Initially the fibre bundles are randomly orientated. In the low-strain area, an increase in strain will align the fibre bundles in the direction of strain according to the so-called fibre bundle recruitment mechanism [34]. Apparently the resistance against aligning of the fibre bundles is low since only small low-strain moduli were observed (Table I). At a certain strain level, most of the fibre bundles have become taut or entrapped in entanglements and an increase in modulus is observed in the transition area.

When the material is elongated further in the highstrain area several events can occur. First, more fibre bundles will become taut or entrapped in entanglements and deformation of these fibre bundles may take place. It has been reported that slippage of fibres or fibrils is possible $[35,36]$ which will eventually result in dissociation of fibres from a fibre bundle. Simultaneously, a process of unravelling of entanglements can take place. In addition, breakage of fibre bundles in this part of the stress-strain curve can be expected, especially when fibre bundles have become taut at low strain values. At high strain values, the number of load-bearing fibre bundles will eventually decrease, resulting in the failure of the material.

From the discussion given above it is clear that the interaction between the fibre/fibre or fibril/fibril surfaces and thus the level at which crosslinks are introduced in the fibre bundle structure are very important parameters when the influence of crosslinking on the mechanical properties of DSC is studied. As can be seen in Table I, no significant differences in elongation at alignment were observed for samples with different degrees of crosslinking indicating that no crosslinks are introduced in between fibre bundles. The increase in low-strain modulus of the G-DSC samples compared to the N-DSC samples may be explained by an increase in modulus of the fibre bundles, resulting in an increased resistance against aligning of the fibre bundle network in the low-strain area.

Treatment of N-DSC samples with GA did not influence the tensile strength of the samples (Table I). Apparently crosslinking, which is known to affect the strength of the fibre bundles [35], does not influence the tensile strength of the N-DSC samples. It is assumed that the principal mode of failure of the material is by slippage and dissociation of the fibres from the fibre bundles and that crosslinks are introduced within the fibres rather than in between fibres. This can also explain why the degree of crosslinking has no influence on the tensile strength of the DSC samples. Whether crosslinks are introduced in between fibrils cannot be concluded from these results because an increased interaction between fibril surfaces does not have to result in an increase in tensile strength if the fibre bundles fail by slippage of the fibres.

The elongation at break of the G-DSC samples increases and the high-strain modulus decreases upon crosslinking. An increase in elongation at break was also observed during the crosslinking of porcine aortic valves [37]. This was ascribed to the crimping of the fibre bundle network during crosslinking which increased the angle of weave of the fibre bundles, resulting in materials with a higher elongation at alignment. However, no change in elongation at alignment after crosslinking was observed in this study. No straightforward explanation can be given for the decrease in high-strain modulus upon crosslinking.

That crosslinks are introduced only within fibres is most likely based on spatial limitations. The average distance between fibres in a fibre bundle is approximately $50 \mathrm{~nm}$ while the average distance between fibre bundles is several orders of magnitude higher. Since no polymeric GA crosslinks are formed as discussed above, the gap between two amine groups on adjacent fibre or fibre bundle surfaces is most likely too large to be bridged by GA crosslinks. This is in contrast with the effects of crosslinking on the mechanical properties of reconstituted collagen. Because reconstituted collagen does not exhibit the highly structured fibrous nature as observed in DSC, no spatial limitations exist during the introduction of crosslinks in the material. Therefore, an increase in tensile strength is always observed after crosslinking of these materials $[38,39]$.

To verify the hypothesis that crosslinks are introduced only within fibres, crosslinking experiments were performed in which the fibre bundle network was aligned. This was achieved by applying a pre-strain equal to the elongation at alignment of the material prior to crosslinking. It is expected that this will decrease the average distance between functional groups on both the fibre bundle and fibre surfaces. Prestrained samples were crosslinked for $1 \mathrm{~h}$ with $0.5 \%$ (w/w) GA using an identical procedure as applied during the non-pre-strained crosslinking. Control experiments were performed by determining the influence of pre-strain ( $1 \mathrm{~h}, 60 \%$ ) without crosslinking on the mechanical properties of N-DSC samples. Both 
the pre-strained non-crosslinked and crosslinked samples were allowed to equilibrate after the pre-strain period for $2 \mathrm{~h}$ during the post crosslinking washing procedure (see Section 2).

As can be seen in Table II, the tensile strength of the control N-DSC samples decreased from $20 \mathrm{MPa}$ to $16 \mathrm{MPa}$, their elongation at alignment decreased from $62 \%$ to $46 \%$ and their elongation at break decreased from $167 \%$ to $136 \%$ compared to non-pre-strained $\mathrm{N}$-DSC samples, respectively. No significant differences were found for the low- and high-strain moduli of these samples. These changes in mechanical properties result from permanent deformation of the fibre bundle network during the pre-strain period due to dissociation of fibres from the fibre bundles or early failure of fibre bundles as discussed above.

When N-DSC samples were subjected to a $60 \%$ pre-strain prior to crosslinking with $\mathrm{GA}$, the tensile strength of the resulting materials increased from $16 \mathrm{MPa}$ to $27 \mathrm{MPa}$. Furthermore the elongation at break decreased from $136 \%$ to $50 \%$ and a large increase in high-strain modulus from $20 \mathrm{MPa}$ to $60 \mathrm{MPa}$ was observed. No low-strain area was present in the stress-strain curves of these samples. These results indicate that upon crosslinking under prestrain, crosslinks are also introduced in between fibres. This was also indicated by the fixation of the prestrain structure during crosslinking as observed by the permanent elongation of the G-DSC samples crosslinked under pre-strain conditions and the morphology of these samples as observed using light microscopy (Figs 15 and 16). These results support the hypothesis that sterical limitations determine at what level crosslinks are introduced in between structural units of the fibre bundle network.

\section{Conclusions}

Schiff bases, resulting from the reaction of glutaraldehyde with free amine groups of lysine or hydroxylysine of dermal sheep collagen (DSC), are formed very rapidly in the beginning of the crosslinking. The hydrolysable Schiff bases are stabilized by further reaction with other glutaraldehyde molecules during the formation of crosslinks. From the relationship between the decrease in free amine group content and the increase in $T_{\mathrm{s}}$ during crosslinking it was concluded that at high glutaraldehyde concentrations and long reaction times pendant GA molecules rather than crosslinks are introduced in the DSC matrix. No evidence for the formation of large polymeric glutaraldehyde related networks during the crosslinking was found Aligning of the fibre bundle network by applying a prestrain to the samples during GA crosslinking resulted also in the formation of crosslinks in between fibres.

\section{References}

1. M. E. NIMNI, D. T. CHEUNG, B. STRATES, M KODAMA and K. SKEIKH, J. Biomed. Mater. Res. 21 (1987) 741.

2. M. ChVAPIL, D. GIBEAULT and T. F. WANG, ibid. 21 (1987) 1383
3. J. M. MCPHERSON, P. W. LEDGER, S. SAWAMURA, A CONTI, S. WADE, H. REIHANIAN and D. G. WALLACE, ibid. 20 (1986) 79.

4. D. T. CHEUNG and M. E. NIMNI, Conn. Tissue Res. 10 (1982) 187

5. J. M. RUIJGROK, M. E. BOON and J. R. de WIJN, Histochem. J. 22 (1990) 389.

6. R. LUBIG, P. KUSCH, K. RÖPER and H. ZAHN, Monatshefte für Chemie 112 (1981) 1313.

7. U. TOMIMATSU, E. F. JANSEN, W. GAFFIELD and A. C. OLSEN, J. Colloid Interface Sci. 36 (1971) 51.

8. D. T. CHEUNG and M. E. NIMNI, Conn. Tissue Res. 10 (1982) 201

9. P. M. HARDY, A. C. NICHOLLS and H. N. RYDON, J. Chem. Soc. Perkin I. (1976) 958.

10. K. OKUDA, I. URABE, Y. YAMADA and H. OKADA, J. Ferm. Bioeng. 71 (1991) 100.

11. E. A. WOODROOF, J. Bioengng 2 (1978) 1.

12. T. J. A. JOHNSON, Eur. J. Cell Biol. 45 (1987) 160.

13. P. M. HARDY, G. J. HUGHES and H. N. RYDON, J. Chem. Soc. Perkin I. (1978) 2282.

14. T. M. VAN GULIK and P. J. KLOPPER, Neth. J. Surg. 39 (1987) 90.

15. L. L. H. HUANG-LEE, D. T. CHEUNG and M. E. NIMNI Biomed. Mater. Res. 24 (1990) 1185.

16. R. GILLET and K. GULL, Histochem. 30 (1972) 162.

17. P. J. FLory and R. R. GARRETT, J. Amer. Chem. Soc. 80 (1958) 4836.

18. Society Leather Trades' Chemists, J. Soc. Leather Trades' Chemists 47 (1963).

19. D. L. GILBERT and S. W. KIM, J. Biomed. Mater. Res. 24 (1990) 1221.

20. C. L. WANG, T. MIYATA, B. WEKSLER, A. L. RUBIN and K. H. STENZEL, Biochim. Biophys. Acta 544 (1978) 555

21. A. VOS and P. J. VAN VLIMMEREN, J. Soc. Leather Technol. Chem. 57 (1973) 93.

22. Society Leather Trades' Chemists, J. Soc. Leather Trades' Chemists, 44 (1960).

23. E. H. BLAAUW, M. F. JONKMAN and P. O. GERRITS, Acta Morphol. Neerl.-Scand. 25 (1987) 167.

24. R. F. BORCH, M. D. BERNSTEIN and H. D. DURST, J. Amer. Chem. Soc. 93 (1971) 2897.

25. D. T. CHEUNG, N. PERELMAN, E. C. KO and M. E NIMNI, Conn. Tissue Res. 13 (1985) 109.

26. J. H. BOWES and C. W. CATER, Biochim. Biophys. Acta 168 (1968) 341

27. S. C. ROE, B. K. MILTHORPE and K. SCHINDHELM Artif. Org. 14 (1990) 443.

28. C. E. VISSER, A. B. E. VOUTE, J. OOSTING, M. E. BOON and L. P. KOK, Biomaterials 13 (1992) 34.

29. C. A. PEREIRA, J. M. LEE and S. A. HABERER, J. Biomed. Mater. Res. 24 (1990) 345.

30. G. A. ROBERTS and K. E. TAYLOR, Makromol. Chem. 190 (1989) 951.

31. E. HEIDEMANN, J. Soc. Leather Techn. Chem. 66 (1982) 21.

32. B. M. HAINES, J. Amer. Leather Chem. Assoc. 77 (1982) 180

33. J. VACULIK, Leder Schuhe Lederwaren 3 (1983) 132.

34. P. L. KRONICK and P. R. BUECHLER, J. Amer. Leather Chem. Assoc. 81 (1986) 221

35. V. MOHANARADHAKRISHNAN, P. L. MUTHIAH and A. HADHANYI, Arzneim.-Forsch. (Drug Res.) 25 (1975) 726.

36. A. HILTNER, J. J. CASSIDY and E. BAER, Ann. Rev. Mater Sci. 15 (1985) 455

37. J. M. LEE, D. R. BOUGHNER and D. W. COURTMAN J. Biomed. Mater. Res. 18 (1984) 79.

38. Y. P. KATO, D. L. CHRISTIANSEN, R. A. HAHN, S. J. SHIEH, J. D. GOLDSTEIN and F. H. SILVER, Biomaterials 10 (1989) 38

39. J. K. LAW, J.R. PARSONS, F. H. SILVER and A. B. WEISS, J. Biomed. Mater. Res. 23 (1989) 961.

Received 11 December 1993

and accepted 20 September 1994 